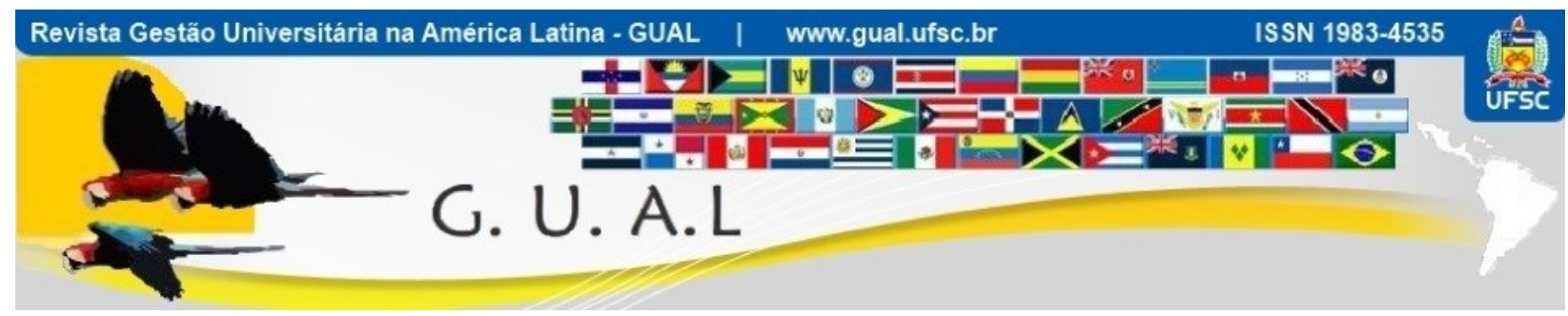

DOI: http://dx.doi.org/10.5007/1983-4535.2013v6n2p106

\title{
PROPOSIÇÃO DE INDICADORES PARA O CORPO DISCENTE E ANÁLISE DE AGRUPAMENTOS APLICADA AOS CURSOS DE GRADUAÇÃO DA UFES
}

\author{
PROPOSITION OF PERFORMANCE INDICATORS FOR STUDENTS AND \\ CLUSTER ANALYSIS APPLIED TO UNDERGRADUATE COURSES AT UFES \\ UNIVERSITY
}

\begin{abstract}
Jaime Souza Sales Junior, Mestre
Universidade Federal do Espírito Santo - UFES jaimesales@hotmail.com

Jádia Petri Penholato, Mestre Universidade Federal do Espírito Santo - UFES jadiapp@gmail.com

Igor da Silva Erler, Mestre Universidade Federal do Espírito Santo - UFES igor.erler@ufes.br

Teresa Cristina Janes Carneiro, Doutora Universidade Federal do Espírito Santo - UFES carneiro.teresa@gmail.com
\end{abstract}

Recebido em 17/março/2013

Aprovado em 09/abril/2013

Sistema de Avaliação: Double Blind Review

Esta obra está sob uma Licença Creative Commons Atribuição-Uso. 


\title{
RESUMO
}

Este estudo propôs a formulação de indicadores de desempenho para o corpo discente para os cursos de graduação da Universidade Federal do Espírito Santo e testou o potencial desses indicadores como classificadores dos cursos de graduação da instituição por meio do método estatístico de análise de agrupamentos. Os indicadores propostos foram: demanda candidato por vaga no vestibular, número de alunos ingressantes, matriculados e diplomados, índice de evasão, envolvimento do discente com pesquisa, índice de reprovação, conceito do Exame Nacional de Desempenho de Estudantes (Enade) e Conceito Preliminar de Curso (CPC). A partir de seis indicadores, a análise de agrupamentos dividiu os 63 cursos analisados em quatro grupos. Os grupos formados mostraram-se heterogêneos, sendo o primeiro formado por cursos com alta demanda no vestibular e alto número de matriculados, o segundo por maior envolvimento com a pesquisa, o terceiro por atraso na integralização do curso e o quarto pelos maiores índices de reprovação e evasão. A análise discriminante foi utilizada para validar os resultados e mostrou um resultado satisfatório, com três funções discriminantes estatisticamente significantes, classificando corretamente $98,6 \%$ das observações sob análise.

Palavras-chave: Indicadores para discentes na graduação. Análise de agrupamentos. Universidade Federal do Espírito Santo.

\begin{abstract}
This study has proposed performance indicators for undergraduate students of Universidade Federal do Espírito Santo (Ufes) and tested the potential use of these indicators as classifiers for the undergraduate courses of that institution by running the statistical method of cluster analysis. The proposed indicators were: number of applicants per vacancy in the entrance system, number of enrolled freshmen, total number of enrolled students, number of degreed students, number of dropout students, number of students engaged in research, failure rate, delay in course completion, ENADE (Student Performance National Exam) grade and CPC (Course Preliminary Concept) grade. Electing six out of these ten indicators, the cluster analysis divided the 63 courses in four very distinct groups. The first group contains courses with high rate of applicants per vacancy and high number of enrolled freshmen; the second group contains courses with high number of students engaged in research; the third group contains courses with high delay in completion; and the fourth group contains courses with high failure and dropout rates. Discriminant analysis was used to validate the results with three discriminant functions statistically significant, and correctly classifying $98.6 \%$ of the cases under analysis.
\end{abstract}

Keywords: Indicators for undergraduate students. Undergraduate courses. Cluster analysis. Discriminant analysis. 


\section{INTRODUÇÃO}

A educação superior do Brasil tem recebido inúmeros esforços por parte do governo e do setor privado, no sentido de melhorar os indicadores de crescimento e os resultados para a sociedade. Foram três as grandes reformas pelas quais o sistema educacional passou até chegar aos moldes atuais: a reforma implementada pela Lei de Diretrizes e Bases da Educação, em 1968 (Lei n. 5.540, 1968), a reforma que aconteceu entre os anos de 1995 e 2000, resultando no crescimento de 32\% no número de instituições (MACEDO, 2005), e a última reforma, sustentada pelo Programa de Apoio a Planos de Reestruturação e Expansão das Universidades Federais (Reuni), implantado pelo Decreto n. 6.096, de 2007, cujo objetivo foi retomar o crescimento das universidades federais, por meio da ampliação do acesso e permanência na educação superior (BRASIL, 2007).

Dentre as universidades que receberam investimentos e, consequentemente, tiveram notável crescimento nas atividades de ensino, pesquisa e extensão, encontra-se a Universidade Federal do Espírito Santo (Ufes), campo da pesquisa do presente trabalho. A Ufes conta hoje com quatro campi, nas cidades de Alegre, São Mateus e dois na capital do Espírito Santo, Vitória. Segundo informações do site institucional, atualmente a universidade possui 93 cursos de graduação, 47 cursos de mestrado e 16 cursos de doutorado, com um quadro de aproximadamente 1.650 professores, 2.500 técnicos administrativos em educação, 20 mil estudantes matriculados na graduação e 2.500 matriculados na pós-graduação. A universidade possui ainda cerca de 600 projetos em curso na área de pesquisa científica e tecnológica e 700 projetos da extensão universitária, abrangendo 1,5 milhão de pessoas em todo o estado (UFES, 2012).

Apesar do forte investimento e crescimento na área de educação no Brasil, grande parte dos gestores das instituições de ensino superior trabalha sem um sistema de controle e gestão por mensuração de indicadores de desempenho (BRESSIANI et al, 2001). Avaliação de desempenho é o processo no qual são definidos indicadores de forma alinhada com a estratégia, missão e objetivos de determinada empresa ou instituição (Crispim, 2012). Segundo Martins (1999), nos indicadores são construídos a partir dos objetivos pretendidos e das metas que surgem a partir deles, as quais servem como dados para avaliar se a meta foi atingida. Crispim (2012) observou que as instituições de ensino superior conferem maior importância primeiramente a indicadores relacionados à satisfação de alunos, ficando em segundo lugar indicadores de demanda, e em terceiro lugar indicadores de qualidade e 
eficiência do ensino. Indicadores financeiros ficam em quarta posição. Além disso, o autor observou que mais de $50 \%$ das IES adotam pelo menos um modelo de avaliação por indicadores em uso, o que mostra a evolução e crescimento desse modelo de gerência dentro da área do ensino. Os gestores não possuem, na maioria das vezes, sistema de medição com indicadores que possuam certo nível de detalhamento e amplitude necessários para uma administração eficiente, utilizando-se de indicadores de desempenho fornecidos pelo Ministério da Educação, através do Sinaes - Sistema Nacional de Avaliação da Educação Superior (Lei n, 10.861, 2004), deixando de avaliar dados importantes como o impacto financeiro dos cursos ou a satisfação dos beneficiados diretos e indiretos. Observa-se que na prática os mecanismos de avaliação propostos pelo Sinaes não possuem a eficácia desejada, frente à expansão do ensino superior e à capacidade limitada do MEC em avaliá-lo (PIRATELLI; BELDERRAIN, 2010).

Aplicado às necessidades das universidades, a construção de um sistema de avaliação mais abrangente se faz necessária como mecanismo de monitoramento e garantia da qualidade, bem como instrumento orientador da gestão acadêmico-administrativa. Tal sistema deve estar preparado para a identificação dos pontos positivos e das fragilidades institucionais e, ainda, ter capacidade de apontar soluções para os problemas presentes. Um sistema de avaliação deve ser capaz de auxiliar no acompanhamento crítico da trajetória institucional em todas as suas dimensões, por meio da mensuração criteriosa do desempenho efetivo e do grau de sua adequação aos planos de desenvolvimento estabelecidos, como diagnóstico do real cumprimento da missão que a instituição assume (MACEDO, 2005).

Diante da urgência e necessidade das instituições de ensino superior iniciar os seus trabalhos de elaboração de um sistema de mensuração do desempenho eficiente, o presente estudo tem por objetivo propor indicadores para o corpo discente dos cursos de graduação da Universidade Federal do Espírito Santo e testar o potencial desses indicadores como classificadores dos cursos da universidade. A classificação visa à redução dos dados através do método estatístico de análise de agrupamento por semelhança de características dos cursos captadas pelos indicadores possibilitando que sejam traçadas estratégias por grupos, simplificando assim o complexo processo de implementação de melhorias. 


\section{METODOLOGIA}

Este estudo caracteriza-se como uma pesquisa descritiva, pois tem como "objetivo primordial a descrição das características de determinada população ou fenômeno ou o estabelecimento de relações entre variáveis" (GIL, 2008). A pesquisa iniciou-se com a seleção dos indicadores a serem trabalhados, seguida de coleta dos dados em sistemas informatizados da Universidade e do Ministério da Educação para o cálculo dos indicadores. Após o cálculo, foram realizadas análises de agrupamentos. Para verificar a validade dos agrupamentos identificados foi realizada uma análise discriminante. As análises estatísticas utilizaram os softwares Statistical Package for the Social Sciences versão 19 (SPSS 19) e Microsoft Office Excel 2010.

\subsection{Formulação de indicadores para o corpo discente da graduação}

Os indicadores propostos nesta pesquisa são apresentados no quadro 1 a seguir. Foram selecionados indicadores das dimensões de input (Demanda, Ingressantes e Matriculados), de output (Diplomados e Índice de Evasão), de processos (Índice de Evasão, Envolvimento com pesquisa, Atraso na Integração e Índice de Reprovação) e de resultados (Enade e CPC).

O indicador "Demanda" representa o quantitativo de candidatos inscritos no vestibular em relação ao número de vagas, por curso, anualmente. O indicador "Ingressantes" representa o número de alunos que ingressaram em determinado curso de graduação, por ano. $\mathrm{O}$ indicador "Matriculados" representa o número de alunos matriculados em todas as disciplinas de um curso de graduação, anualmente. $\mathrm{O}$ indicador "Diplomados" representa o número de indivíduos que colaram grau oficialmente naquele ano, por curso de graduação. $\mathrm{O}$ indicador "Índice de Evasão" aponta o percentual de alunos evadidos do curso, em todos os tipos de evasão excluída a evasão por falecimento, em relação aos alunos matriculados em todas as disciplinas, no ano analisado. O indicador "Envolvimento com pesquisa" representa o percentual de alunos que possuem vínculo com atividades de pesquisa, considerando os bolsistas remunerados e voluntários, em relação ao total de alunos matriculados, por curso de graduação, no ano analisado. O indicador "Atraso na Integração" foi calculado por meio da subtração entre o tempo médio de conclusão do curso (em anos) pelos alunos de determinado curso no ano analisado e o tempo padrão de integração do curso, este último determinado no projeto pedagógico do curso. O indicador "Índice de Reprovação" aponta o percentual de reprovação em relação ao número de matriculados em todas as disciplinas do curso naquele 
ano. Os indicadores "Enade" e "Conceito Preliminar de Curso" (CPC) são calculados e divulgados pelo MEC. O Enade é valor contínuo do conceito associado ao Teste Enade e CPC leva em consideração no seu cálculo o Enade, o Indicador de Diferença entre o Desempenho Observado e o Esperado, a infraestrutura, os recurso didáticos, a qualificação e a dedicação do corpo docente dos cursos de graduação.

Os indicadores Enade e CPC foram obtidos no site do Instituto Nacional de Estudos e Pesquisas Educacionais Anísio Teixeira (Inep) e todos os demais foram calculados com base em dados secundários extraídos do Sistema de Informações para Ensino (SIE), que é sistema utilizado pela Pró-Reitoria de Planejamento e Desenvolvimento Institucional (Proplan/Ufes). Todas as informações são referentes ao ano 2011. Para indicadores CPC e Enade foi considerada a informação mais recente de cada curso, uma vez que o ciclo de aplicação do Exame é de três anos, não havendo, portanto, dados anuais.

\begin{tabular}{|l|l|l|}
\hline Indicador & Descrição & $\begin{array}{l}\text { Fonte } \\
\text { dados }\end{array}$ \\
\hline Demanda & $\begin{array}{l}\text { Número de candidatos inscritos no vestibular dividido } \\
\text { pelo número de vagas oferecidas pelo curso. }\end{array}$ & SIE/Ufes \\
\hline Ingressantes & Número de alunos ingressantes & SIE/Ufes \\
\hline Matriculados & Número de alunos matriculados & SIE/Ufes \\
\hline Diplomados & Número de alunos diplomados & SIE/Ufes \\
\hline $\begin{array}{l}\text { Índice } \\
\text { Evasão }\end{array}$ & $\begin{array}{l}\text { Número de alunos evadidos dividido pelo número de } \\
\text { alunos matriculados }\end{array}$ & SIE/Ufes \\
\hline $\begin{array}{l}\text { Envolvimento } \\
\text { com pesquisa }\end{array}$ & $\begin{array}{l}\text { Número de alunos que possuem bolsa de pesquisa dividido } \\
\text { pelo número de alunos matriculados }\end{array}$ & SIE/Ufes \\
\hline $\begin{array}{l}\text { Atraso } \\
\text { Integração }\end{array}$ & $\begin{array}{l}\text { Diferença entre o tempo, em anos, padrão de integração do } \\
\text { curso e tempo médio de integralização do curso dos } \\
\text { alunos do respectivo curso }\end{array}$ & SIE/Ufes \\
\hline $\begin{array}{l}\text { Índice } \\
\text { Reprovação }\end{array}$ & $\begin{array}{l}\text { Número de reprovações dividido pelo total de matriculas } \\
\text { em disciplinas do curso }\end{array}$ & SIE/Ufes \\
\hline ENADE & $\begin{array}{l}\text { Último conceito do curso no Exame Nacional de } \\
\text { Desempenho de Estudantes }\end{array}$ & Site INEP \\
\hline CPC & Último Conceito Preliminar de Curso & Site INEP \\
\hline
\end{tabular}

Quadro 1 Indicadores

No cálculo dos indicadores foram considerados 91 cursos de graduação presenciais. Os cursos Licenciatura dupla Português e Espanhol e Licenciatura dupla Português e Francês 
foram desconsiderados na análise por terem sido ofertados apenas uma única vez, possuindo apenas uma turma de alunos.

\section{ANÁLISE DOS DADOS}

\subsection{Análise de agrupamentos}

Segundo Fávero et al (2009), a análise de agrupamento, também conhecida como cluster analysis ou análise de conglomerados, é uma técnica estatística de interdependência que fornece critérios para agrupar objetos que podem ser pessoas, empresas, produtos, cursos, etc., a partir de similaridades, de tal forma que os objetos sejam homogêneos em seus grupos e os grupos sejam heterogêneos entre si. O objetivo da análise é utilizar uma estrutura "natural" criada a partir dos objetos.

A análise de agrupamentos pode ajudar a identificar outliers e sugerir relações hipotéticas a respeito das relações entre os objetos. Esta análise vem sendo utilizada em diversas áreas do conhecimento como Psicologia, Biologia, Sociologia, Economia, Engenharia e a Administração (BELFIORE et al, 2005).

Nesta pesquisa, a análise de agrupamentos tem como objetivo identificar grupos estruturados que permitam avaliar similaridades entre os cursos da Ufes a partir dos indicadores propostos anteriormente.

\subsection{Análise discriminante}

A análise discriminante, ou discrminant analysis, é uma técnica estatística multivariada que visa relacionar uma variável qualitativa com conjunto de variáveis quantitativas (BELFIORE et al, 2005). Os objetivos principais do método são (a) utilizar um vetor de observações multivariadas para classificar um objeto em um grupo (FERREIRA, 2008), (b) identificar variáveis que melhor discriminam os grupos em questão e (c) criar regras de alocação para um novo objeto a partir das funções discriminante (FÁVARO, 2009). Porém, Ferreira (2008) adverte que, apesar de muito útil para classificar um novo caso, é necessário considerar que existe a possibilidade de um agrupamento incorreto.

O método consiste em obter funções discriminantes resultantes de combinações lineares de variáveis independentes e, a partir delas, classificar os objetos nos grupos. Corrar et al (2009) afirmam que a análise discriminante vem sendo utilizada para diversas 
finalidades, como por exemplo, finanças e marketing. A análise discriminante pode ser utilizada também para validar a análise de agrupamentos (FÁVERO, 2009).

\section{RESULTADOS}

\subsection{Indicadores para o corpo discente da graduação}

A tabela 1 e a figura 1 exibem uma análise descritiva dos resultados do cálculo dos indicadores da Ufes.

Tabela 1 Estatísticas Descritivas - Indicadores

\begin{tabular}{lccccc}
\hline & N & Mínimo & Máximo & Média & Desvio-padrão \\
\hline Demanda & 91 & 0,70 & $46,86^{\mathrm{i}}$ & 5,80 & 5,96 \\
Ingressantes & 91 & $4^{\mathrm{ii}}$ & $129^{\mathrm{iii}}$ & 53,5 & 24,5 \\
Matriculados & 91 & $21^{\mathrm{iv}}$ & $601^{\mathrm{v}}$ & 190,7 & 122,8 \\
Diplomados & 91 & 0 & $108^{\mathrm{vi}}$ & 21,6 & 23,7 \\
Índice de evasão & 91 & 0,000 & $0,852^{\mathrm{vii}}$ & 0,084 & 0,103 \\
Índice de Reprovação & 91 & 0,070 & 0,680 & 0,270 & 0,147 \\
Atraso na Integração & 65 & $-0,420$ & 3,150 & 0,754 & 0,783 \\
Envolvimento & $\mathrm{a}$ & 0,000 & 0,284 & 0,074 & 0,067 \\
pesquisa & 91 & 0,205 & 4,940 & 3,037 & 1,378 \\
ENADE & 25 & 0,744 & 4,550 & 3,050 & 0,787 \\
CPC & 45 & & &
\end{tabular}

Da análise da tabela acima pode-se observar que os cursos analisados tiveram em média 5,8 candidatos por vaga nos processos seletivos (exames vestibulares) e que a maior relação candidato/vaga foi no curso de Medicina $(46,86)$, sendo este um valor altamente discrepante. Outro dado que chama a atenção é o curso Matemática - São Mateus (Bacharelado) que teve apenas 4 ingressantes, apesar de oferecer 50 vagas no vestibular.

O gráfico Box-Plot evidencia também que, quando comparado aos demais, o curso de Direito apresenta valores positivamente discrepantes para Demanda, Ingressantes, Matriculados e Diplomados.

O valor mínimo zero para o número de alunos diplomados ocorre em cursos novos que ainda não possuem alunos formados, ou seja, existem há menos tempo do que o período necessário para integralização do curso. Da mesma forma, o indicador Atraso na Integralização apresentou 65 observações, resultado de 26 cursos da Ufes que ainda não tiveram alunos formados, o que inviabiliza o cálculo deste indicador para esses cursos. 


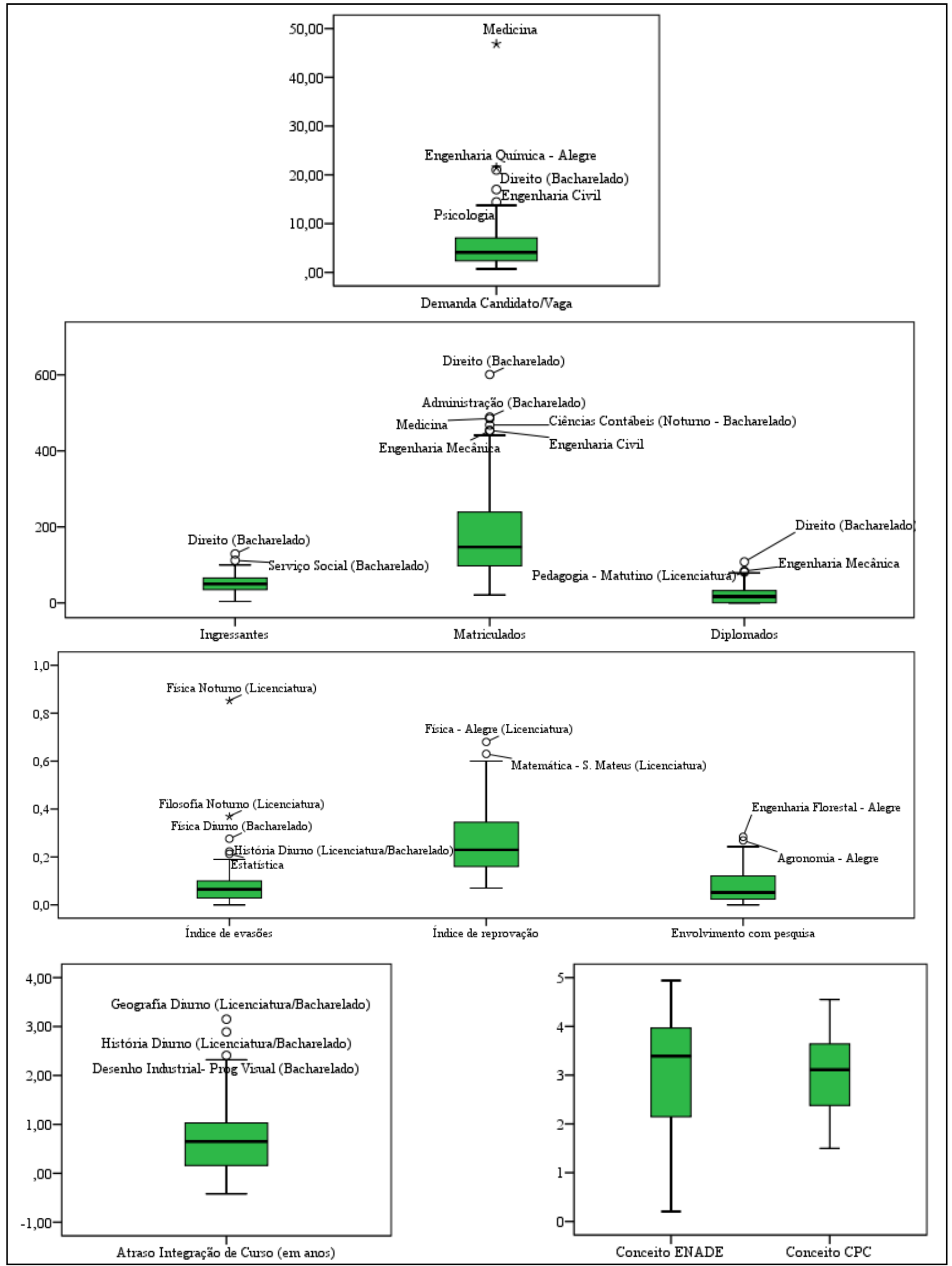

Figura 1 Box-Plot - Indicadores. 


\section{PROPOSIÇÃO DE INDICADORES PARA O CORPO DISCENTE E ANÁLISE DE AGRUPAMENTOS \\ APLICADA AOS CURSOS DE GRADUAÇÃO DA UFES \\ DOI: http://dx.doi.org/10.5007/1983-4535.2013v6n1p1}

Analisando o Índice de Evasão, é possível ver que curso Física - Noturno apresentou mais de 85\% de evasão em 2011. O Conceito Preliminar de Curso (CPC) está disponível para 45 cursos - nem todos os cursos são avaliados pelo MEC por meio do Enade. Este conceito varia numa escala de 0 à 5 . Nos resultados, é possível observar um valor mínimo de 0,744 , referente ao curso de Educação Física - Licenciatura.

Tabela 2 Coeficiente de Correlação de Pearson (r) - Indicadores

\begin{tabular}{|c|c|c|c|c|c|c|c|c|c|c|c|}
\hline & & Demanda & Ingressantes & Matriculados & Diplomados & $\begin{array}{l}\text { Índice de } \\
\text { evasão }\end{array}$ & $\begin{array}{l}\text { Índice de } \\
\text { reprovação }\end{array}$ & $\begin{array}{l}\text { Atraso na } \\
\text { Integração }\end{array}$ & $\begin{array}{l}\text { Envolv. } \\
\text { com } \\
\text { pesquisa }\end{array}$ & ENADE & $\mathrm{CPC}$ \\
\hline Demanda & $\mathrm{R}$ & 1,000 & 0,265 & 0,474 & 0,483 & $-0,225$ & $-0,302$ & $-0,199$ & 0,042 & $-0,017$ & $-0,006$ \\
\hline \multirow{2}{*}{ Ingressantes } & $\mathrm{R}$ & 0,265 & 1,000 & 0,787 & 0,542 & $-0,216$ & $-0,364$ & 0,058 & $-0,326$ & $-0,308$ & $-0,381$ \\
\hline & p-valor & 0,011 & & 0,000 & $\mathbf{0 , 0 0 0}$ & 0,040 & $\mathbf{0 , 0 0 0}$ & 0,647 & 0,002 & 0,134 & $\mathbf{0 , 0 1 0}$ \\
\hline \multirow{2}{*}{ Diplomados } & $\mathrm{R}$ & 0,483 & 0,542 & 0,834 & 1,000 & $-0,123$ & $-0,523$ & $-0,014$ & 0,007 & $-0,300$ & $-0,266$ \\
\hline & p-valor & $\mathbf{0 , 0 0 0}$ & $\mathbf{0 , 0 0 0}$ & 0,000 & & 0,247 & $\mathbf{0 , 0 0 0}$ & 0,913 & 0,947 & 0,145 & 0,078 \\
\hline \multirow{2}{*}{$\begin{array}{l}\text { Índice de } \\
\text { evasão }\end{array}$} & $\mathrm{R}$ & $-0,225$ & $-0,216$ & $-0,237$ & $-0,123$ & 1,000 & 0,283 & 0,162 & 0,166 & 0,050 & $-0,121$ \\
\hline & p-valor & 0,032 & 0,040 & 0,024 & 0,247 & & 0,006 & 0,198 & 0,115 & 0,813 & 0,429 \\
\hline $\begin{array}{l}\text { Índice de } \\
\text { reprovação }\end{array}$ & $\mathrm{R}$ & $\begin{array}{l}-0,302 \\
\end{array}$ & $-0,364$ & $-0,528$ & $-0,523$ & 0,283 & 1,000 & $-0,038$ & $-0,055$ & 0,421 & 0,264 \\
\hline $\begin{array}{l}\text { Envolv. com } \\
\text { pesquisa }\end{array}$ & p-valor & 0,695 & $\mathbf{0 , 0 0 2}$ & 0,080 & 0,947 & 0,115 & 0,604 & 0,214 & & 0,190 & 0,092 \\
\hline \multirow{2}{*}{ ENADE } & $\mathrm{R}$ & $-0,017$ & $-0,308$ & $-0,262$ & $-0,300$ & 0,050 & 0,421 & $-0,201$ & 0,271 & 1,000 & 0,953 \\
\hline & p-valor & 0,934 & 0,134 & 0,205 & 0,145 & 0,813 & 0,036 & 0,358 & 0,190 & & 0,000 \\
\hline \multirow{2}{*}{$\mathrm{CPC}$} & $\mathrm{R}$ & $-0,006$ & $-0,381$ & $-0,240$ & $-0,266$ & $-0,121$ & 0,264 & $-0,140$ & 0,254 & 0,953 & 1,000 \\
\hline & $\mathrm{p}$-valor & 0,967 & 0,010 & 0,113 & 0,078 & 0,429 & 0,080 & 0,371 & 0,092 & 0,000 & \\
\hline
\end{tabular}

A tabela 2 e a figura 2 mostram correlação linear entre os indicadores propostos. Nestes resultados é possível notar que, a um nível de 5\% de significância, a Demanda possui relação positiva com Número de Ingressantes, Matriculados e Diplomados e relação negativa com os Índices de Evasão e Reprovação. Daí pode-se sugerir que, quanto maior é a procura no vestibular, maior é o número de alunos no curso e que aqueles cursos com maiores Índices de Evasão e Reprovação são menos procurados no vestibular. É possível verificar também que os Índices de Evasão e Reprovação estão positivamente relacionados entre si, daí pode-se sugerir que aquele aluno que reprova está mais propenso a abandonar o curso e ambos são negativamente relacionados aos indicadores Número de Ingressantes, Matriculados e Diplomados. Assim, como esperado, a Reprovação e Evasão impactam negativamente nos outros três indicadores citados. Além disso, o Enade e CPC apresentam-se altamente 
relacionados, o que também já era esperado, uma vez que cálculo do conceito CPC engloba o Enade em sua composição.

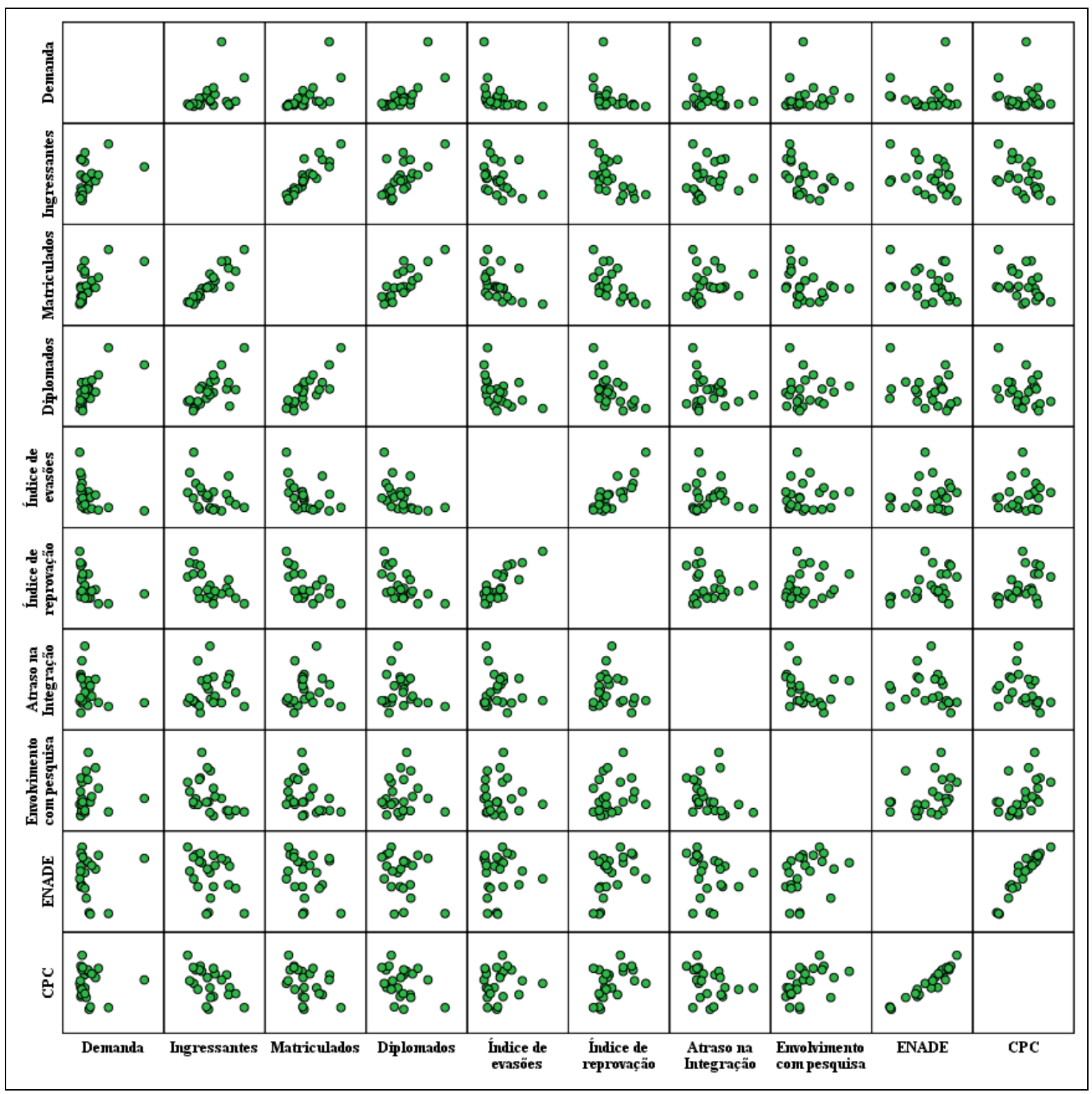

Figura 2 Gráfico de Dispersão - Indicadores.

\subsection{Análise de agrupamentos}

Ao fazer a análise de agrupamentos é necessário que se analise primeiro a presença de outliers dentre os objetos estudados e a multicolinearidade entre as variáveis (FÁVERO et al, 2009). Analisando o coeficiente linear de Pearson dos indicadores do estudo, observa-se que os indicadores Ingressantes e Diplomados são altamente associados ao Número de Alunos Matriculados $(0,737$ e 0,834 , respectivamente $)$. Por este motivo optou-se por retirar os 
indicadores Ingressantes e Diplomados desta análise. Além disso, os cursos Física Noturno (Licenciatura) e Filosofia Noturno (Licenciatura) apresentam valores de evasão extremamente altos e altamente discrepantes, portanto optou-se por retirar estes cursos da análise de agrupamentos. Os demais pontos discrepantes não foram retirados da análise por se entender que, apesar de discrepantes, refletem a realidade estudada. Também foram retirados da análise os cursos que não possuem a informação do tempo de integralização. Além disso, considerando que os indicadores Enade e CPC possuem apenas 25 e 45 observações respectivamente, estes indicadores também não foram considerados na análise de agrupamentos.

O método de agrupamento escolhido foi o método hierárquico aglomerativo utilizando o procedimento de Ward para formação dos agrupamentos. Para eliminar o efeito da magnitude dos indicadores, foi feita a padronização para scores padrão ${ }^{\text {viii }}$. Analisando o dendograma (figura 4), percebe-se a formação de quatro grandes grupos, a linha tracejada no nível de distância 10 ajuda a percebê-los. Estes grupos estão descritos no quadro 2.

\begin{tabular}{|c|c|c|c|}
\hline Grupo 1 & Grupo 2 & Grupo 3 & Grupo 4 \\
\hline $\begin{array}{l}\text { - Administração } \\
\text { (Bacharelado) } \\
\text { - Arquitetura e } \\
\text { Urbanismo } \\
\text { - Ciências } \\
\text { Econômicas } \\
\text { (Bacharelado) } \\
\text { - Direito } \\
\text { (Bacharelado) } \\
\text { - Educação Física } \\
\text { (Licenciatura) } \\
\text { - Engenharia } \\
\text { Civil } \\
\text { - Engenharia } \\
\text { Elétrica } \\
\text { - Engenharia } \\
\text { Mecânica } \\
\text { - Medicina } \\
\text { - Odontologia } \\
\text { - Pedagogia - } \\
\text { Matutino } \\
\text { (Licenciatura) } \\
\text { - Psicologia } \\
\text { - Serviço Social } \\
\text { (Bacharelado) }\end{array}$ & $\begin{array}{l}\text { - Agronomia - Alegre } \\
\text { - Agronomia - São Mateus } \\
\text { - Ciências Biológicas Alegre } \\
\text { (Bacharelado) } \\
\text { - Ciências Biológicas São } \\
\text { Mateus (Bacharelado) } \\
\text { - Enfermagem } \\
\text { - Engenharia de Alimentos - } \\
\text { Alegre } \\
\text { - Engenharia de Petróleo - São } \\
\text { Mateus } \\
\text { - Engenharia de Produção } \\
\text { - Engenharia Florestal - Alegre } \\
\text { - Engenharia Química - São } \\
\text { Mateus } \\
\text { - Farmácia } \\
\text { - Farmácia - São Mateus } \\
\text { - Geologia - Alegre } \\
\text { - História Noturno } \\
\text { (Licenciatura/Bacharelado) } \\
\text { - Letras - Inglês (Licenciatura) } \\
\text { - Letras - Português Noturno } \\
\text { (Licenciatura) } \\
\text { - Medicina Veterinária - } \\
\text { Alegre } \\
\text { - Química (Bacharelado) }\end{array}$ & $\begin{array}{l}\text { - Arquivologia (Vespertino / Noturno - } \\
\text { Bacharelado) } \\
\text { - Artes Plásticas (Bacharelado) } \\
\text { - Artes Visuais (Licenciatura) } \\
\text { - Biblioteconomia (Noturno - Bacharelado) } \\
\text { - Ciência da Computação (Bacharelado) } \\
\text { - Ciências Biológicas } \\
\text { (Licenciatura/Bacharelado) } \\
\text { - Ciências Contábeis (Vespertino - } \\
\text { Bacharelado) } \\
\text { - Ciências Sociais (Noturno - } \\
\text { Licenciatura/Bacharelado) } \\
\text { - Comunicação Social - Jornalismo } \\
\text { (Bacharelado) } \\
\text { - Comunicação Social - Publ. Prop. } \\
\text { (Bacharelado) } \\
\text { - Desenho Industrial- Prog Visual } \\
\text { (Bacharelado) } \\
\text { - Engenharia Ambiental } \\
\text { - Engenharia de Computação } \\
\text { - Engenharia de Produção - São Mateus } \\
\text { - Geografia Diurno } \\
\text { (Licenciatura/Bacharelado) } \\
\text { - Geografia Noturno } \\
\text { (Licenciatura/Bacharelado) } \\
\text { - História Diurno } \\
\text { (Licenciatura/Bacharelado) } \\
\text { - Letras - Português Matutino } \\
\text { (Licenciatura) } \\
\text { - Música (Licenciatura) } \\
\text { - Nutrição - Alegre } \\
\text { - Oceanografia }\end{array}$ & $\begin{array}{l}\text { - Ciências Sociais } \\
\text { (Vespertino - } \\
\text { Licenciatura/Bacharelado } \\
\text { ) } \\
\text { - Enfermagem - São } \\
\text { Mateus } \\
\text { - Engenharia Industrial } \\
\text { Madeireira -Alegre } \\
\text { - Estatística } \\
\text { - Filosofia Noturno } \\
\text { (Bacharelado) } \\
\text { - Física Diurno } \\
\text { (Bacharelado) } \\
\text { - Matemática } \\
\text { (Licenciatura/Bacharelad } \\
\text { o) } \\
\text { - Matemática - S. Mateus } \\
\text { (Bacharelado) } \\
\text { - Química (Licenciatura) } \\
\text { - Tecnologia Mecânica } \\
\text { (Noturno) } \\
\text { - Zootecnia - Alegre }\end{array}$ \\
\hline
\end{tabular}

Quadro 2 Grupos da análise de agrupamentos. 
A figura 4 mostra o gráfico de radar e a tabela 3 traz estatísticas descritivas, as quais evidenciam a caracterização dos grupos a partir da construção natural dos mesmos. Nestes, percebe-se a heterogeneidade entre os grupos e observa-se que o grupo 1 caracteriza-se pelo alto número de matriculados, alta demanda e menores índices de reprovação e de envolvimento com pesquisa e evasão. No grupo 2, destaca-se o alto envolvimento dos discentes com pesquisa, moderada demanda no vestibular e moderado índice de evasão. $\mathrm{O}$ grupo 3 apresenta cursos com altos índices de atraso na integralização do curso, moderado número de matriculados e baixo envolvimento do discente com a pesquisa. Por fim, no grupo 4 estão alocados os cursos com maiores índices de evasão e reprovação e menor número de matriculados.

\subsection{Análise dos grupos}

Grupo 1 - Este é o grupo com alto número de matriculados, alta demanda e menores índices de reprovação, de evasão e de envolvimento com pesquisa. Nesse grupo estão os cursos que têm procura no processo seletivo, o que leva à seleção mais efetiva dos alunos mais bem preparados que se reflete nos baixos índices de reprovação durante o curso. Chama a atenção nesse grupo o baixo envolvimento de alunos com pesquisa, o que pode denotar tratar-se de cursos com mais alta empregabilidade e um foco maior na formação profissional do que científica.

Grupo 2 - Este é o grupo com alto envolvimento dos discentes com pesquisa, moderada demanda no vestibular e moderado índice de evasão. Nesse grupo estão os cursos que têm um foco maior na formação científica do discente ou que possuem um número maior de discentes interessados nessa formação. Isso, em parte, pode justificar uma demanda menor no vestibular.

Grupo 3 - Este é o grupo com alto índice de atraso na integralização do curso, moderado número de matriculados e baixo envolvimento do discente com a pesquisa. Nesse grupo estão os cursos que exigem uma competência específica dos alunos o que pode explicar o atraso na integralização (dificuldade de avançar nas disciplinas) e o baixo envolvimento em pesquisa uma vez que a atenção do aluno fica concentrada na aprovação nas disciplinas.

Grupo 4 - Este é o grupo com maiores índices de evasão e reprovação e menor número de matriculados. Nesse grupo estão os cursos que exigem mais atenção da universidade e uma análise mais detalhada das suas características uma vez que altos índices 
de evasão são um indicador preocupante. Pode-se tratar de cursos que reúnem várias características dos grupos anteriores simultaneamente, a saber: cursos com poucas oportunidades de trabalho para os alunos depois de formados na região em que são oferecidos, cursos que exigem uma competência específica dos alunos, cursos em que o processo seletivo é menos disputado, selecionando alunos mal preparados para as exigências das disciplinas que precisam cursar.

\subsection{Análise Discriminante}

Em princípio, a análise discriminante considerou os seis indicadores padronizados como variáveis independentes e foi utilizado o procedimento stepwise de seleção com $5 \%$ de significância para inclusão e $10 \%$ para exclusão das variáveis independentes associado à estatística Lambda de Wilks. A partir do procedimento, cinco indicadores foram selecionados: Matriculados, Índice de Evasão, Índice de Reprovação, Atraso na Integralização e Envolvimento com pesquisa. Ou seja, o indicador de Demanda não foi incluindo no modelo.

$\mathrm{Na}$ análise, o valor da estatística Lambda de Wilks igual a 0,27 associado ao p-valor menor que 0,001 indica que o modelo tem baixa probabilidade de classificar incorretamente os cursos sob análise.

As tabelas 4 e 5 trazem a matriz de estrutura e os eingenvalues das funções. Através da matriz de estrutura observa-se que as os indicadores Matriculados, Índice de Reprovação e Índice de Evasão são mais relevantes para função discriminante 1 e os indicadores Atraso na Integralização e Envolvimento com a Pesquisa são mais relevantes para a função discriminante 2. Já em relação aos eigenvalues, observa-se que a função discriminante 1 explica $63,3 \%$ da variabilidade do modelo e a função discriminante 2 explica $22,7 \%$ do variabilidade, ou seja, as duas juntas explicam $86 \%$ da variabilidade. 
64

Conmuricação Social - Jomalismo (Bacharelado) Conwuicação Social - Publ. Prop. (Bacharelado)

Engenharia Ambiental

Oceanografía

Ciências Sociais (Notumo - Licenciatura/Bacharelado)

Nutrição - Alegre

Engenharia De Prochução - São Mateus

Ciência da Computação (Bacharelado)

Engenharia de Computação

Artes Plásticas (Bacharelado)

Artes Visuais (Licenciatura)

Desenho Inchstrial- Prog Vivual (Bacharelado)

Geografia Notumo (Licenciatura/Bacharelado)

Letras - Português Matutino (Licenciatura)

Arquivologia (Vespertino/Notumo - Bacharelado)

Ciências Contabeis (Vespertino - Bacharelado)

Biblioteconomia (Notumo - Bacharelado)

Música (Licenciatura)

Ciências Biológicas (Licenciatura/Bacharelado)

Geografia Diumo (Licenciatura/Bacharelado)

História Diumo (Licenciatura/Bacharelado)

Engenharia Civil

Engenhlaria Mecânica

Direito (Bacharelado)

Administração (Bacharelado)

Engenharia Elétrica

Ciências Econômicas (Bacharelado)

Pedagogia - Matutino (Licenciatura)

Serviço Social (Bacharelado)

Educação Física (Licenciatura)

Arquitetura e Urbanismo

$>$ Odontologia

Psicologia

Medicina

Ciências Sociais (Vespertino - Licenciatura/Bacharelado)

Física Diumo (Bacharelado)

Enfermagem - São Mateus

Zootecruia - Alegre

Filosofia Notumo (Bacharelado)

Estatística

Tecnologia Mecânica (Notumo)

Engenharia Inctustrial Madeireira-Alegre

Química (Licenciatura)

Matemática (Licenciatura/Bacharelado)

Matemática - S. Mateus (Bacharelado)

Enfermagem

Medicina Veterinária - Alegre

Agronomia - Alegre

Engenharia Florestal - Alegre

Engenharia Quínica - São Mateus

Famácia

Agronomia - \$ão Mateus

Ciências Biológicas São Mateus (Bacharelado)

Famnácia - São Mateus

Ciências Biológicas Alegre (Bacharelado)

Letras - Inglês (Licenciatura)

Química (Bacharelado)

Engenharia de Petróleo - São Mateus

Engenharia de Alimentos - Alegre

História Notumo (Licenciatura/Bacharelado)

Geologia - Alegre

Letras - Português Notumo (Licenciatura)

Engenharia de Prochução

0
Distância - Método de Ward

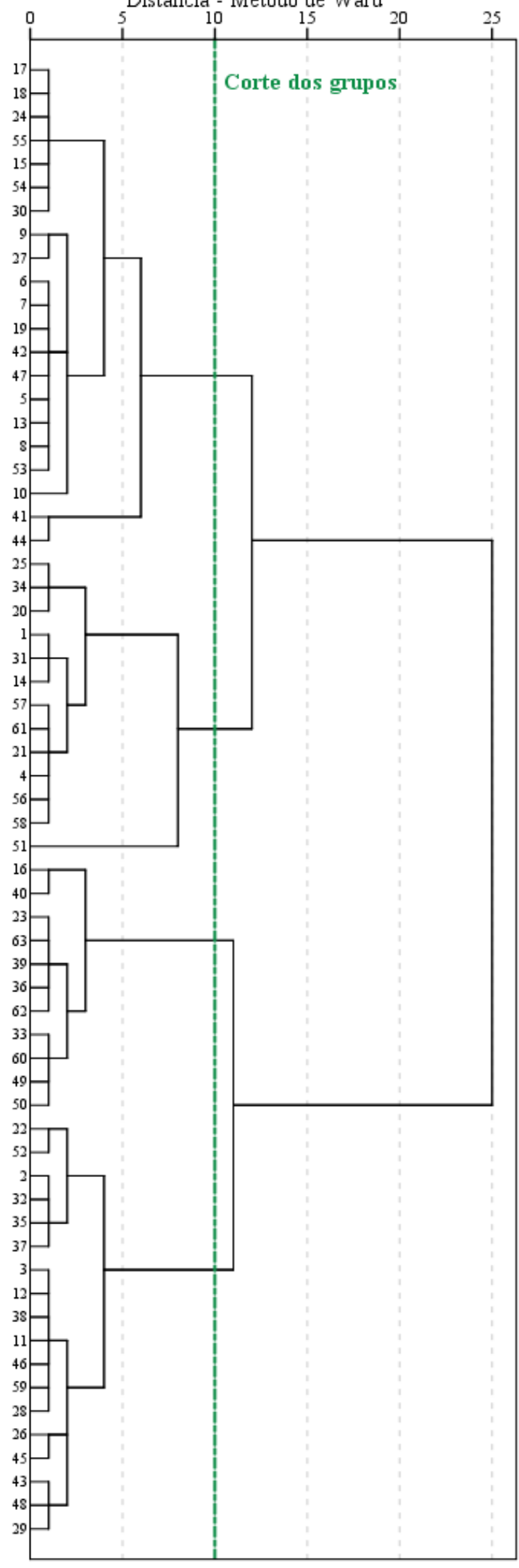

Figura 3 Dendograma - Método de Ward 


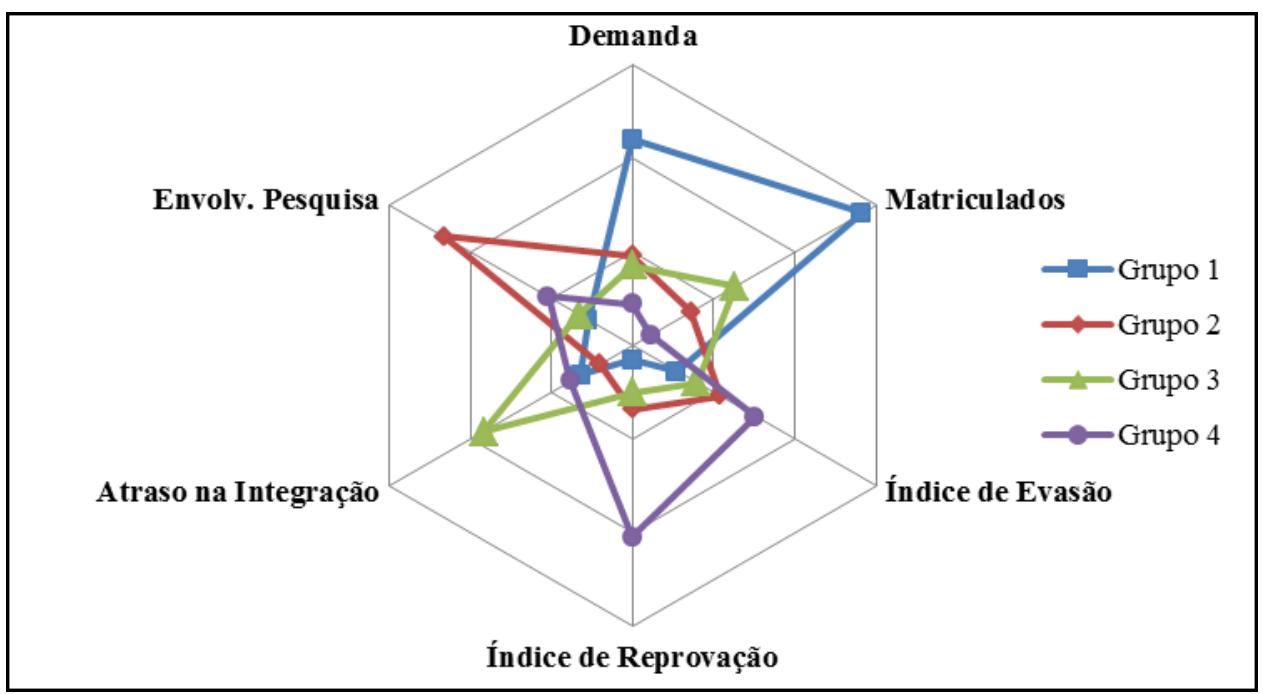

Figura 4 Gráfico Radar - Média dos indicadores padronizados por grupo

Tabela 3 Estatísticas Descritivas - Indicadores Por grupo

\begin{tabular}{lccccccccc}
\hline & \multicolumn{1}{c}{ Grupo 1 $(\mathrm{n}=13)$} & Grupo 2 $(\mathrm{n}=18)$ & Grupo 3 $(\mathrm{n}=21)$ & Grupo $4(\mathrm{n}=11)$ \\
\cline { 2 - 10 } & Média & $\begin{array}{c}\text { Desvio- } \\
\text { Padrão }\end{array}$ & Média & $\begin{array}{c}\text { Desvio- } \\
\text { Padrão }\end{array}$ & Média & $\begin{array}{c}\text { Desvio- } \\
\text { Padrão }\end{array}$ & Média & $\begin{array}{c}\text { Desvio- } \\
\text { Padrão }\end{array}$ \\
\hline Demanda & 12,93 & 11,64 & 5,57 & 3,04 & 4,93 & 2,63 & 2,50 & 1,59 \\
Matriculados & 416 & 84 & 156 & 45 & 223 & 66 & 95 & 48 \\
Índice de evasões & 0,038 & 0,034 & 0,092 & 0,045 & 0,062 & 0,053 & 0,137 & 0,068 \\
Índice de reprovação & 0,145 & 0,053 & 0,222 & 0,066 & 0,196 & 0,057 & 0,424 & 0,058 \\
Atraso na Integração & 0,468 & 0,375 & 0,282 & 0,419 & 1,408 & 0,890 & 0,566 & 0,619 \\
Envolv. Pesquisa & 0,044 & 0,033 & 0,162 & 0,065 & 0,051 & 0,047 & 0,077 & 0,051 \\
\hline
\end{tabular}

Tabela 4 Matriz de estrutura

\begin{tabular}{lccc}
\hline & \multicolumn{3}{c}{ Função } \\
\cline { 2 - 4 } & $\mathbf{1}$ & $\mathbf{2}$ & $\mathbf{3}$ \\
\hline Matriculados & $-0,765$ & 0,015 & 0,458 \\
Índice de reprovação & 0,641 & $-0,046$ & 0,635 \\
Índice de evasão & 0,289 & 0,080 & 0,101 \\
Atraso na integração & $-0,040$ & $-0,545$ & $-0,178$ \\
Envolvimento com & 0,189 & 0,544 & $-0,482$ \\
pesquisa & & & \\
\hline
\end{tabular}

Tabela 5 Eigenvalues

\begin{tabular}{cccc}
\hline Função & Eigenvalue & $\begin{array}{l}\text { \% da } \\
\text { Variância }\end{array}$ & \% Acumulado \\
\hline 1 & 5,151 & 63,3 & 63,3 \\
2 & 1,847 & 22,7 & 86,0 \\
3 & 1,135 & 14,0 & 100,0 \\
\hline
\end{tabular}


$\mathrm{Na}$ tabela 6 observa-se que os valores da estatística Lambda de Wilks são consideravelmente distantes de 1,0 e o p-valor do Teste Qui-Quadrado são menores que 0,001. Em outras palavras, é possível afirmar que as três funções discriminantes possuem alto poder discriminantes e são altamente significantes.

Tabela 6 Lambda de Wilks e Qui-Quadra para as funções

\begin{tabular}{cccc}
\hline Teste de Função & Lambda de Wilks & Qui-Quadrado & p-valor \\
\hline 1 para 3 & 0,027 & 208,215 & 0,000 \\
2 para 3 & 0,165 & 103,763 & 0,000 \\
3 & 0,468 & 43,601 & 0,000 \\
\hline
\end{tabular}

$\mathrm{Na}$ figura 5 é possível ver as centroides dos grupos baseados nas funções discriminantes 1 e 2 . Apesar de ser um gráfico bidimensional e não contemplar a função discriminante 3, é possível ter-se uma ideia da dispersão das observações em torno dos centroides e verificar que, de um modo geral, as observações de cada grupo se concentraram em torno da sua respectiva centroide. Já na tabela 7 vemos como as funções discriminantes classificam cada uma das observações, nela pode-se notar que apenas um curso foi classificado incorretamente, isto é, 98,4\% das observações foram corretamente classificadas, o que corrobora o alto poder discriminante do modelo ajustado na análise.

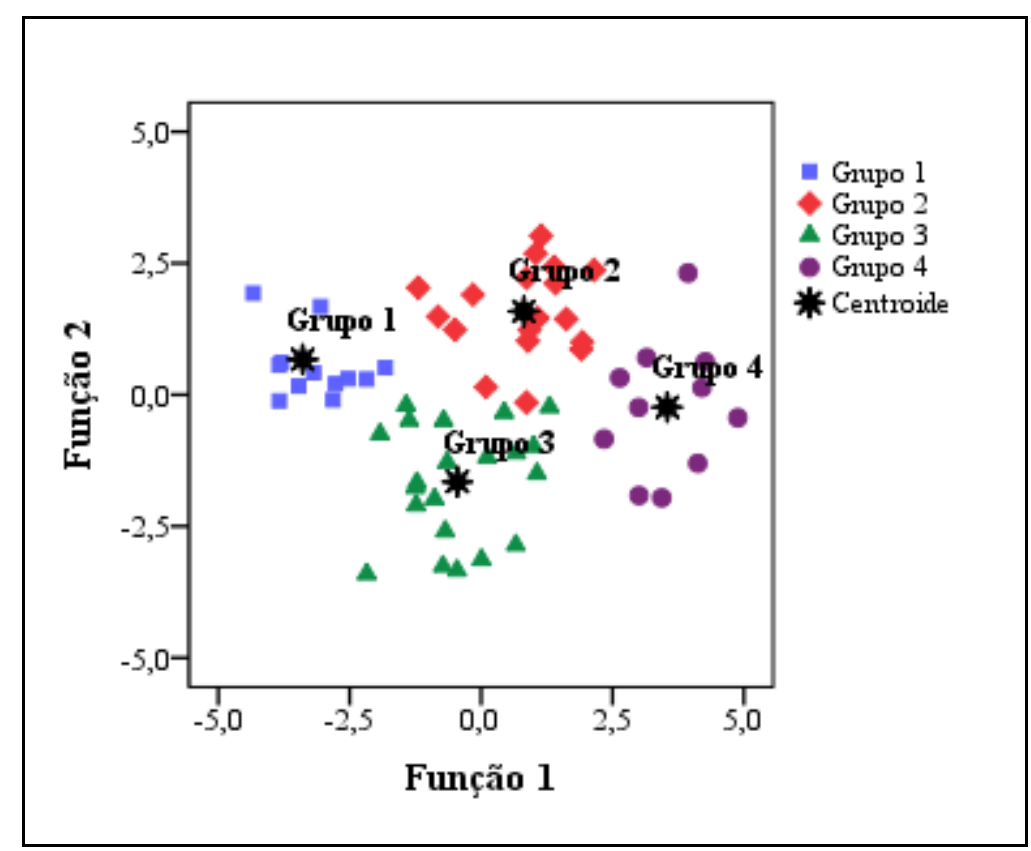

Figura 5 Centroides das funções discriminantes 
Tabela 7 Tabela de Classificação

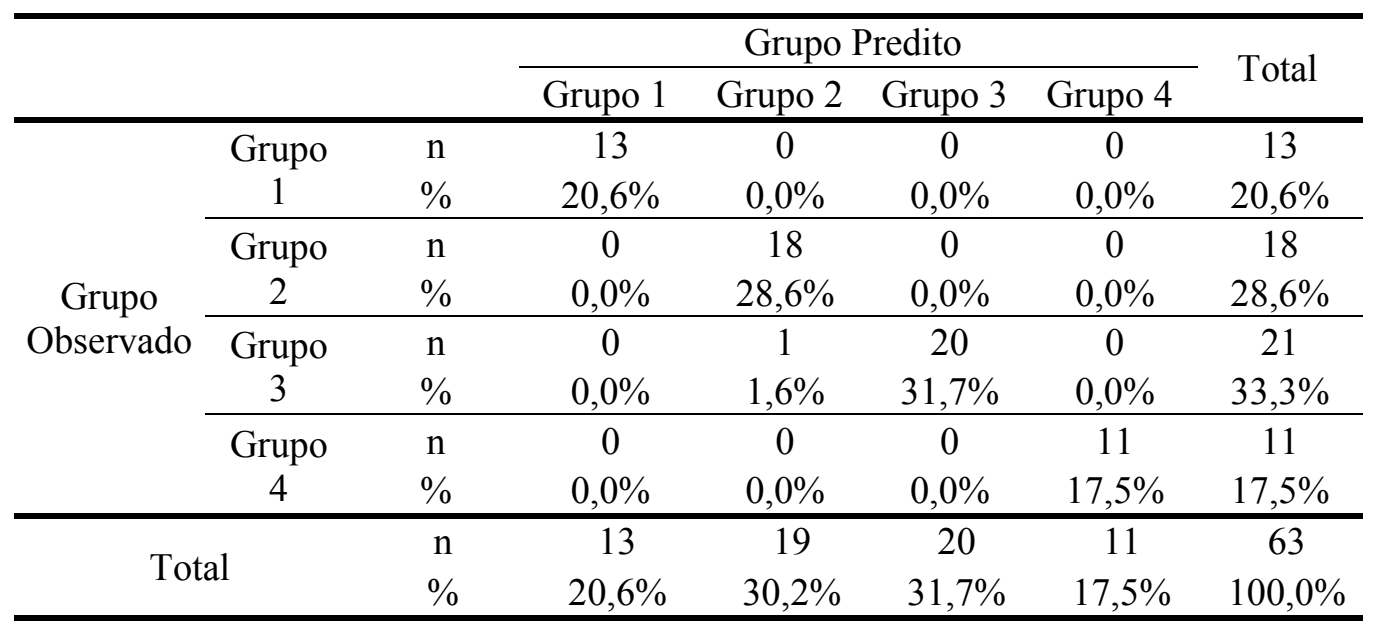

\section{CONCLUSÕES}

Foram propostos, para acompanhamento contínuo, 10 indicadores para os cursos de graduação da Ufes relacionados aos discentes. A análise dos mesmos mostrou que existem cursos com comportamentos atípicos (outliers) que, em alguns casos, podem merecer investigação mais profunda sobre a razão deste comportamento.

A análise de correlação linear de Pearson revelou como os indicadores estão relacionados entre si e mostrou que a demanda no vestibular está positivamente relacionada com o número de alunos ingressantes, matriculados e diplomados do curso e negativamente relacionada com o índice de evasão e reprovação. Os índices de reprovação e evasão estão negativamente relacionados ao número de alunos ingressantes, matriculados e diplomados e são positivamente relacionados entre si. A partir desses resultados sugere-se uma análise mais aprofundada sobre os motivos de alguns cursos terem pouca demanda no vestibular e traçar estratégias para melhorar esse indicador, uma vez que este impacta nos resultados do curso para a sociedade. Uma possível explicação é a baixa empregabilidade dos alunos depois de formados na região em que o curso está sendo oferecido. Nesse sentido as estratégias possíveis são a redução de oferta de vagas ou a busca de opções de empregos para os alunos fora da região. Outra opção é a falha na divulgação da proposta do curso, atraindo poucos interessados e com perfil adequado.

$\mathrm{Na}$ análise de agrupamentos foram considerados 63 cursos e seis indicadores. A análise dividiu os cursos em quatro grupos. O Grupo 1 se destacou por ter alta demanda no vestibular, alto número de matrículas, baixo índice de reprovação e pouco envolvimento dos discentes com pesquisa e baixo índice de evasão. O Grupo 2 possui moderada demanda no 
vestibular e moderado índice de evasão e é o grupo em que os discentes tem maior envolvimento com a pesquisa. $\mathrm{O}$ grupo 3 tem os maiores índices de atraso na integralização do curso e baixo envolvimento com pesquisa. Já o grupo 4 destaca-se com os maiores índices de evasão e reprovação, sendo esse último grupo o que mais demanda atenção da universidade.

A análise discriminante foi realizada para validar a análise de agrupamentos. Foram estimadas três funções discriminantes com valores Lambdas de Wilks distantes de um e estatisticamente significantes ( $\mathrm{p}$-valor $<0,001$ ). $\mathrm{O}$ modelo estimado pela análise discriminante foi capaz de classificar corretamente $98,4 \%$ das observações.

Para trabalhos futuros, sugere-se fazer uma investigação qualitativa para uma possível explicação da existência de alguns valores discrepantes no cálculo dos indicadores e as características mais marcantes dos grupos formados, bem como um estudo considerando não somente as características do corpo discente nos indicadores, mas aquelas relacionadas ao corpo docente, como qualificação e regime de trabalho.

\section{REFERÊNCIAS}

BELFIORE, P. P.; FÁVERO, L. P. L.; ANGELO, C. F. Análise multivariada para avaliação do comportamento de grupos supermercadistas brasileiros. Administração em Diálogo, nº7, p. 53-75, 2005.

BRASIL. Lei n. 10.861, de 14 de abril de 2004. Institui o Sistema Nacional de Avaliação da Educação Superior - SINAES e dá outras providências. Diário Oficial [da] República Federativa do Brasil, Poder Executivo, Brasília, DF, 15 abr. 2004. Disponível em: $<$ http://www.planalto.gov.br/>. Acesso em: 07 set. 2012.

. Lei n. 5.540, de 28 de novembro de 1968. Fixa normas de organização e funcionamento do ensino superior e sua articulação com a escola média, e dá outras providências. Diário Oficial [da] República Federativa do Brasil, Brasília, DF, 29 nov. 1968 e retificada em 3 dez. 1968. Disponível em: <http://www.planalto.gov.br/>. Acesso em: 02 set. 2012.

. Decreto n. 6.096, de 24 de abril de 2007. Institui o Programa de Apoio a Planos de Reestruturação e Expansão das Universidades Federais - REUNI. Diário Oficial [da] República Federativa do Brasil, Brasília, DF, 25 abr. 2007. Disponível em: $<$ http://www.planalto.gov.br/>. Acesso em: 16 set. 2012.

BRESSIANI, F.; ALT, P. R. C.; MASSOTE, A. A. O uso do Balanced Scorecard como instrumento de melhoria de desempenho de uma instituição de ensino superior. In: CONGRESSO BRASILEIRO DE ENSINO DE ENGENHARIA (COBENGE), XXIX, 2001, Porto Alegre. Anais. 
FÁVERO, L. P. et al. Análise de dados: modelagem multivariada para tomadas de decisões. São Paulo: Elsevier, 2009.

FERREIRA, D. F. Estatística multivariada. 1.ed. Lavras: UFLA, 2009.

GIL, A. C. Métodos e técnicas de pesquisa social. 6. ed. São Paulo: Atlas, 2008.

MACEDO, A. R.; TREVISAN, L. M. V.; TREVISAN, P.; MACEDO, C. S. Educação superior no século XXI e a reforma universitária brasileira. Revista Ensaio: Avaliação e Políticas Públicas em Educação, v.13, n. 47, p. 127-148, abr./jun. 2005.

MARIO, P. C. Análise discriminante. In: CORRAR, Luiz J.; PAULO, Edilson; DIAS FILHO, José M. (Org.). Análise multivariada para cursos de administração, ciências contábeis e economia. 1.ed. São Paulo: Atlas, 2009.

PIRATELLI, Claudio L.; BELDERRAIN; MISCHEL C. N. Apoio à fase de projeto de um sistema de medição de desempenho com o strategic options development and analysis (SODA). IN: SIMPÓSIO DE ADMINISTRAÇÃO DA PRODUÇÃO, LOGÍSTICA E OPERAÇÕES INTERNACIONAIS, XIII, 2010, Rio de Janeiro. Anais.

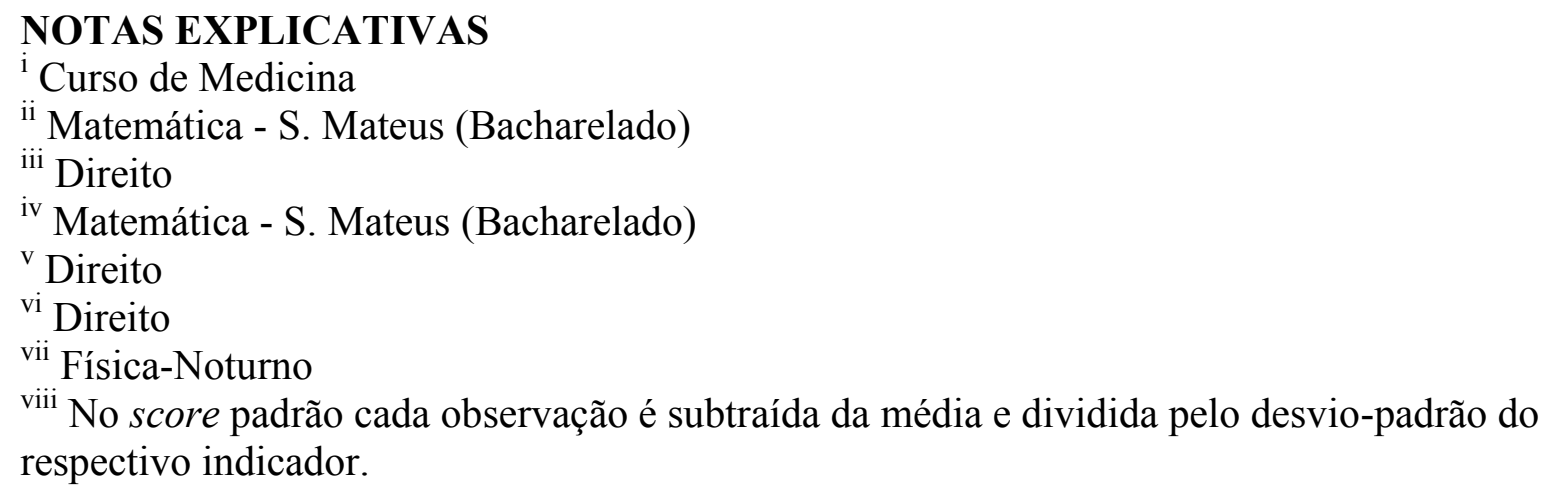

